\title{
Creando posesión vía desposesión. Visitas a la tierra y conformación de resguardos indígenas en la Vega de Supía, 1559-1759
}

Setting Possession by Dispossession. Land Inspections (visitas a la tierra) and the Creation of Indigenous Landholdings in the Vega de Supia, 1559-1779

DOI: https://doi.org/10.22380/20274688.819

Recibido: 28 de junio del 2019

Aprobado: 10 de enero del 2020
GLORIA PATRICIA LOPERA MESA*

Florida International University, EE.UU. glope161@fiu.edu

\section{R E S U M E N}

Este artículo explora el papel de las visitas a la tierra en la creación de territorios indígenas en un área periférica de la Nueva Granada conocida como la Vega de Supía (hoy Riosucio y Supía, Caldas). Afirma que mientras las primeras visitas, como la de Tomás López Medel (1559), se centraron en controlar el tributo y el trabajo indígena, la demarcación de resguardos solo comenzó durante el segundo ciclo de visitas. La visita de Lesmes de Espinosa Saravia a la Vega de Supía (1627) muestra que estas operaron como un mecanismo de despojo a través del reasentamiento de población y el trazado de linderos. Asimismo, al definir y fijar por escrito estos linderos, las visitas establecieron, en términos de legalidad colonial, los derechos de los indígenas sobre sus resguardos, proveyendo evidencia que en siglos

* Abogada y magíster en antropología de la Universidad de Antioquia. Doctora en derecho de la Universidad de Castilla-La Mancha. Candidata a doctora en historia de la Florida International University (FIU). Investiga sobre el uso de títulos coloniales por parte de litigantes indígenas para afrontar los procesos de disolución de resguardos en Colombia en el período 1873-1950. https:// orcid.org/0000-000I-620I-9282 
posteriores sería utilizada para definir reclamos territoriales. Así, de manera paradójica, estas visitas establecieron posesión vía desposesión.

Palabras clave: visitas a la tierra, resguardos indígenas, derechos territoriales, Vega de Supía, Anserma, Nuevo Reino de Granada.

\section{$\begin{array}{llllllllllllllllllll}\mathbf{A} & \mathbf{B} & \mathbf{S} & \mathbf{T} & \mathbf{R} & \mathbf{A} & \mathbf{C} & \mathbf{T}\end{array}$}

This article explores the role of land inspections (visitas a la tierra) in the creation of indigenous territories in a peripheral area of Nueva Granada known as Vega de Supía (present-day Riosucio and Supía, Caldas). It claims that whereas early inspections, such as Tomás López Medel's (1559), focused on Indian tribute and labor, the demarcation of indigenous resguardos only started during the second cycle of inspections. As exemplified by the 1627
Lesmes de Espinosa's territorial rearrangement in the Vega de Supía, inspections created dispossession by removing natives from, or setting boundaries on, the lands that they had occupied before. Yet, by setting up and writing down boundaries, these inspections made legible in colonial terms indigenous land rights, providing legal grounds to settle future conflicts over land. Thus, paradoxically, these inspections set up possession by dispossession.

Keywords: land inspections, resguardos indígenas, land rights, Vega de Supía, Anserma, Nuevo Reino de Granada.

Estos indios y todos los demás de este distrito se valen para sus pedimentos de las ordenanzas del Sr. Don Lesmes.

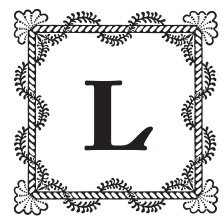

as visitas constituyeron uno de los principales mecanismos administrativos empleados por la corona española para hacer cumplir la legislación, obtener información y, en general, ejercer soberanía sobre sus colonias (Céspedes; Sánchez). Un tipo específico de visitas, conocidas como "visitas a la tierra", eran inspecciones practicadas con cierta regularidad por los oidores de la Real Audiencia con el fin de hacer cumplir en terreno la legislación sobre indígenas (Ruiz). Germán Colmenares distingue dos ciclos en la práctica de estas visitas en el Nuevo Reino de Granada: las del primer ciclo (I550-I572), que se concentraban en determinar

I $\quad$ AGN, SC, $R$, doc. 25 , f. $6 \mathrm{I} 2 \mathrm{v}$. 
la población tributaria, tasar los tributos y fiscalizar el cumplimiento de reglas relativas al trabajo y el tributo indígena; y las del segundo ciclo (I593-I635), las cuales se ocupaban además de la creación de pueblos de indios y la delimitación de tierras de resguardo $(79)^{2}$.

Este artículo explora el papel de las visitas a la tierra en la configuración de territorios indígenas en la Vega de Supía, un centro minero situado en jurisdicción de la ciudad de Anserma, provincia de Popayán. Con tal fin, se comparan las dos primeras visitas a esta zona de las cuales se conservan registros: la practicada en I559 por el oidor Tomás López Medel y la efectuada en I627 por el oidor Lesmes de Espinosa Saravia. Estas visitas ilustran la diferencia entre ambos ciclos: la primera se concentra en fiscalizar la apropiación por parte de los encomenderos sobre el trabajo y el tributo indígena; la de I627, además de lo anterior, delimita resguardos indígenas y plantea una reordenación territorial de la Vega de Supía que tendrá importantes consecuencias en lo sucesivo.

La historiografía sobre visitas a la tierra en Nueva Granada se ha concentrado principalmente en la zona de los Andes orientales (actuales departamentos de Boyacá, Cundinamarca y Santander). Dichos estudios muestran que el establecimiento de resguardos en la zona comenzó a partir de 1593, asociado a la legislación sobre composición de tierras de I59I. Esta literatura también destaca las consecuencias de este proceso en términos de desposesión y reconfiguración del paisaje y la ordenación del territorio (Fals-Borda; Friede, "De la encomienda"; Bonnet; Herrera Ordenar; González). El rol de las visitas a la tierra en la región andina del centro-occidente ha sido menos explorado. Juan Friede examina las visitas a la provincia de Cartago, entre ellas la de López Medel y Espinosa Saravia. Aunque limitado a Cartago, el estudio de Friede ilustra el cambio de énfasis entre ambas visitas, pasando del control sobre el trabajo y el tributo indígena a una mayor preocupación por el control del territorio (Los Quimbaya). Las visitas a la región de Anserma no han sido estudiadas en profundidad. Luis Javier Caicedo analiza algunos apartes de la visita de 1627, a fin de mostrar su importancia en la creación de territorialidades indígenas en el actual municipio de Riosucio (Cinco 7-27). Sin embargo, Caicedo no contrasta la visita de 1627 con la practicada por López Medel en I558-I559 y, por tanto, no da cuenta del cambio de énfasis de cuestiones de trabajo y tributo indígena a cuestiones territoriales.

2 Jaime Jaramillo Uribe añade un tercer ciclo de visitas a la tierra, practicadas de 1750 en adelante (“La Administración Colonial” 180). 
Este artículo busca contribuir al estudio del proceso de formación de territorios indígenas en la Vega de Supía durante el periodo I559-I759; asimismo, aporta al debate académico sobre el significado histórico de la creación de resguardos, al poner en evidencia el carácter dual de este proceso en términos de desposesión de tierras. Por un lado, la creación de resguardos representó un mecanismo de "despojo pacífico y legal” que, en el caso de la sabana de Bogotá, implicó la pérdida de cerca del $95 \%$ de las tierras que antes estaban en manos indígenas (Friede, "De la encomienda" 53); pero, a la vez, al demarcar los linderos de las tierras de resguardo, las titulaciones efectuadas en las visitas a la tierra proveyeron evidencia escrita con la cual respaldar los reclamos territoriales indígenas (Quiroga 194). Desde esta perspectiva, la creación de resguardos representó un mecanismo para asegurar protección legal a las tierras indígenas en un momento en que la memoria del pasado prehispánico empezaba a desvanecerse y el recurso a documentos comenzó a desplazar los argumentos de ancestralidad como fundamento de derechos sobre la tierra (Herzog 308; Owensby IoI).

A partir del examen de la Vega de Supía, este artículo analiza el impacto de las visitas del segundo ciclo sobre la territorialidad indígena. Por un lado, estas visitas fueron un mecanismo de desposesión por cuanto el establecimiento de resguardos implicó en algunos casos el reasentamiento de población nativa en zonas distintas a las que habitaban antes de la colonización; para los indígenas que no fueron removidos, la creación de resguardos implicó el trazado de linderos sobre las tierras que estos venían ocupando, lo que puede considerarse una medida regresiva si se compara con la situación preexistente, en la cual las tierras que los indígenas tenían derecho a ocupar no estaban delimitadas. Por otro lado, al fijar por escrito los linderos de los resguardos, los registros de visitas hicieron legibles en términos de la legalidad colonial los derechos de los nativos sobre sus tierras, proveyendo evidencia que en siglos posteriores sería utilizada para zanjar disputas territoriales. Por tanto, de manera paradójica, estas visitas establecieron posesión vía desposesión.

Para desarrollar este argumento, la primera parte del artículo sintetiza los elementos centrales de la política indigenista impulsada por la corona espańola en la segunda mitad del siglo xvi y el rol de la institución de la visita de tierras en su puesta en práctica. En la segunda parte se comparan las visitas a la región de Anserma efectuadas por Tomás López Medel (I558-1559) y Lesmes de Espinosa Saravia (1627). La tercera parte explora las consecuencias de la visita de I627 en la creación de territorialidades indígenas en la Vega de Supía, 
a través del examen de una disputa de tierras que tuvo lugar entre los indios de Cañamomo y Supía entre 1757 y 1759.

\section{Del control del trabajo y del tributo indígena al control de las tierras. La política sobre los indígenas en la segunda mitad del siglo xv I y el rol de las visitas a la tierra en su implementación}

Con el propósito de facilitar la exacción de trabajo y tributo indígena y a la vez proteger a los nativos como "vasallos libres de la corona", a partir de la década de I540, la Corona impulsó una política basada en dos estrategias centrales: de un lado, limitar el poder de los encomenderos de extraer tributo y trabajo de los indios; de otro, el proceso de reducción o concentración territorial de la población nativa.

Para lograr lo primero, durante la segunda mitad del siglo XVI se adoptaron medidas conducentes a tasar los tributos, prohibir a los encomenderos emplear a sus indios en servicios personales, fijar la tributación por cabeza y excluir a los encomenderos del cobro de los tributos. En 549 se ordenó tasar la clase y la cantidad de tributo que deberían pagar los naturales en el Nuevo Reino de Granada. Esta medida generó gran resistencia entre los encomenderos quienes, en el caso de la provincia de Popayán, llegaron al extremo de boicotear la tasación. Esto motivó al obispo de Popayán, Juan del Valle, a introducir en I554 una "tasa arbitraria" llamada a regir hasta tanto la Real Audiencia no fijara una tasa oficial (Friede, Vida I08-IIo; Colmenares I40). Adicionalmente, se ordenó suprimir el tributo en trabajo para circunscribirlo al pago en especie (pesos de oro, mantas, productos agrícolas, animales de caza y cría, entre otros); se reemplazó la tasación colectiva con la tributación por cabeza para evitar cargar a los tributarios con la parte de los muertos y ausentes. Finalmente, tras la implementación de la figura del corregidor de indios en 1593 , se prohibió a los encomenderos intervenir en el cobro de los tributos (Eugenio 225-332; Colmenares I35-I6I).

La segunda estrategia de la política proteccionista consistió en el reasentamiento y concentración territorial de la población nativa. Aunque las primeras instrucciones de la Corona para reunir a los indios en pueblos datan de 1503 y se reiteran a lo largo de la primera mitad del siglo xvi, fue solo a partir de la 
segunda mitad de ese siglo cuando se profirieron regulaciones que comprendían el territorio de la Nueva Granada, como es el caso de la Cédula Real del 2I de marzo de 155 I dirigida al gobernador de la provincia de Tierra Firme, o las instrucciones proferidas en 1559 por Tomás López Medel para juntar y poblar a los naturales de Santafé (Mörner; Solano, Cedulario I09, I7I I8I; Herrera, "Ordenamiento" IoI; Reina 36-47; Romero 63-73)³.

La congregación de los nativos en "pueblos de indios", separados de las ciudades, villas y lugares en los que residían españoles (y otra población no indígena), estructuró el dualismo entre la "República de españoles" y la "República de indios" que caracterizó el orden sociolegal de la Colonia. Con ella se buscaba habituar a los nativos a "vivir en policía" en un entorno urbano y evitar el mal ejemplo que generaba el contacto con los españoles (Mörner 2-4I). Además de servir a los objetivos políticos y espirituales de la empresa colonial, la política de reducciones facilitó el recaudo del tributo, el control sobre la mano de obra nativa, el abastecimiento y sustento de las ciudades y, de manera indirecta, la apropiación de las tierras nativas (Reina 48-57).

La reorganización territorial de la población nativa involucró varios momentos: su reducción a pueblos de indios; el alinderamiento de resguardos o tierras destinadas al laboreo y sustento de los nativos; la posterior agregación de unos pueblos a otros y, hacia el final del periodo colonial, la extinción de los pueblos de indios y su transformación en parroquias de blancos y mestizos. Aunque algunos trabajos clásicos sobre el tema presentan las dos primeras operaciones como concomitantes (Fals-Borda; González), la historiografía más reciente enfatiza la diferencia temporal y de objetivos entre la creación de pueblos de indios y la delimitación de resguardos, sin perder de vista que constituyeron dos momentos dentro del proceso de trazar las fronteras entre las "dos repúblicas" (Herrera, Ordenar I80-I82; Quiroga I8I; Reina).

La reducción a pueblos de indios fue un proceso complejo, extendido en el tiempo y resistido por los nativos. Dependía de que los encomenderos efectivamente cumplieran con su obligación de construir templos doctrineros y viviendas para los indios y de que estos últimos ciertamente se asentaran en ellas. En tal sentido, Reina Mendoza distingue entre la mera reducción y el entable de los pueblos; mientras la primera implicaba establecer un punto de congregación en torno a una enramada o capilla improvisada, el entable comprendía no solo 
la traza y la construcción de estructuras físicas, sino la conformación de aparatos de gobierno (79-179). Además de la traza urbana, también formaban parte de los pueblos de indios las tierras dedicadas al cultivo, a la caza y a la cría de ganado, así como las tierras que los nativos poseían antes de la llegada de los españoles (Mörner 48, I68-I72; Salcedo I88-198; Herrera, Ordenar 89, I76-I80). Vista desde la perspectiva de la legislación, la política de tierras indígenas impulsada por la Corona en la segunda mitad del siglo xvi buscaba mantener a los indígenas en posesión de las que tradicionalmente habían ocupado, y a la vez garantizarles tierras adicionales en los pueblos en los que serían reasentados ${ }^{4}$. Para este momento, la demarcación de las tierras indígenas no era todavía una preocupación que estuviera presente ni en la legislación ni en la manera en que las autoridades implementaban la política de reducciones sobre el terreno.

Las cosas comenzaron a cambiar a partir de I59I cuando Felipe II expidió las llamadas Cédulas del Pardo, con el propósito de aprovechar la tierra en las Indias como una fuente de recursos fiscales, necesarios para afrontar el incremento en gastos militares 5 . Para ello, se requirió a quienes poseyeran tierras para que acreditaran títulos válidos y en caso de carecer de ellos legalizar su ocupación mediante el pago de una suma por determinar, en un procedimiento conocido como composición de tierras. La reforma de I59I llegó en un momento en el que los encomenderos buscaban nuevas fuentes de ingresos para compensar el declive del tributo como consecuencia del descenso de la población nativa. Las composiciones permitieron a los encomenderos convertirse en propietarios de tierras que hasta entonces habían ocupado de facto y fueron determinantes para el desarrollo del sistema de hacienda. Asimismo, al garantizar a los nativos el derecho a ocupar las tierras "que hubieren menester para hacer sus labores y sementeras y crianzas”, dicha legislación introdujo un mecanismo que, tiempo después, sería utilizado por las autoridades coloniales para reducir las tierras indígenas a aquellas estrictamente necesarias para asegurar la subsistencia de la población nativa (Solano, Cedulario 270; Graubart 75). En tal contexto, el alinderamiento de las tierras indígenas adquirió importancia para las autoridades

Una cédula real de 1560 establecía que "se reducirán a poblaciones los indios, si no se les quitan las tierras y granjerías que tuvieren en los sitios que dejaren. Mandamos que en esto no se haga novedad, y se les conserven como las hubieren tenido antes" (Recopilación, t. II, lib. vi, tít. III, ley IX). Entre tanto, una cédula real de 1573 disponía que "los sitios en que se han de formar pueblos y reducciones tengan comodidad de aguas, tierras y montes... y un ejido de una legua de largo, donde los indios puedan tener sus ganados" (Recopilación, t. II, lib. VI, tít. III, ley VIII). 
coloniales, para los españoles que aspiraban a legalizar sus posesiones y para los propios nativos que experimentaban creciente presión sobre sus tierras. En el caso del Nuevo Reino de Granada, las tierras así demarcadas se denominaron resguardos y su delimitación coincidió con, y resultó funcional a, la política de composición de tierras (Colmenares 217-231; Salcedo 184; Friede, "De la encomienda" 53; Solano, Ciudades 344; Herrera, Ordenar I80-I8I).

Las visitas a la tierra fueron el mecanismo a través del cual se implementaron los aspectos de la política indigenista examinados en esta sección ${ }^{6}$. En el Nuevo Reino de Granada, el primer ciclo de visitas a la tierra (I550-I572) comprendió la región centro-oriental, las provincias de Cartagena y Santa Marta y la gobernación de Popayán. Su finalidad principal fue cuantificar la población tributaria, tasar los tributos y fiscalizar el cumplimiento de reglas relativas al trabajo y el tributo indígena. Aunque en ellas también se impartían órdenes para reducir a los naturales a pueblos y construir doctrinas, dichas órdenes no fueron atendidas o lo fueron de manera precaria, sin que por sí mismas hayan dado lugar a la consolidación de pueblos de indios (López y Ares; Mojica 7-22; Eugenio I29-I68; Luna 43; Quiroga I82-I86; Reina 8I-IO3).

Durante la presidencia de Antonio González se inicia un segundo ciclo de visitas en las cuales, sin desatender lo relativo a tributo, trabajo y trato dispensado a los nativos por curas y encomenderos, la configuración del territorio pasa a ocupar un lugar central. Este ciclo inicia con las visitas efectuadas por Miguel de Ibarra a Santafé en I593, Egaz de Guzmán a Tunja en 1595 y Luis Henríquez a Tunja y Santafé entre I60I-I603, con las que se consolida el entable de pueblos de indios y la alinderación de resguardos en el altiplano (Quiroga I9I-I96; Reina II3-I20). Este proceso continúa con las visitas de Antonio Beltrán de Guevara a Pamplona entre I60I y I602; Juan de Villabona Zubiaurre a Cartagena en I6II y Pamplona en 1623; Francisco de Herrera Campuzano a Antioquia en 1614, Lesmes de Espinosa Saravia a Vélez, Muzo y la Palma en I6r7, así como a los distritos de Anserma, Arma, Cartago, Toro, Ibagué, Tocaima y Mariquita en I627; Antonio Rodríguez de San Isidro al valle del Cauca y Pasto en I637. Este

6 La regulación de las visitas a la tierra se encuentra agrupada en la Recopilación, t. I, lib. II, tit. Xxxi, "De los oidores, visitadores ordinarios de los distritos de audiencias y chancillerías reales de las Indias", en un título distinto del destinado a otros tipos de visitas (t. I, lib. II, tit. Xxxıv, "De los visitadores generales y particulares"). Véase, además, Recopilación, t II, lib. vi, tit. III, "De las reducciones y pueblos de indios”. Para un detenido análisis de la regulación de las visitas a la tierra, su periodicidad y estructura véase Céspedes; Sánchez; Ruiz; Eugenio. 
ciclo se cierra con las visitas llevadas a cabo por Jacinto de Vargas Campuzano a Vélez, Moniquirá y Sorocota en 1670 y a Cartagena en I675 (Mojica; Montoya y González; Colmenares 23I-240; Luna 46-6I, 205-269).

La relación de la visita de Miguel Ibarra a Santafé en 1593 establece la pauta a seguir en las visitas correspondientes al segundo ciclo. Además de disposiciones sobre numeración de los indios, su adecuada doctrina, trabajo y tributo, o la recepción de información secreta sobre el trato dispensado a estos por curas y encomenderos, la relación de Ibarra contiene instrucciones sobre "cómo se ven las tierras y se da resguardo" y cómo distribuirlas entre los naturales de cada pueblo. Así, a un pueblo de 400 a 500 tributarios (equivalente a una población total de 2.000 personas, según cálculos del visitador) correspondían 3.000 pasos de tierra en redondo, contados "desde las postreras casas y buyos de cada pueblo". La extensión por adjudicar se determinaba en cada caso en función del número de indios y la calidad de la tierra. Las tierras así delimitadas debían ser repartidas por el corregidor "dando a los caciques más que a los capitanes y a los capitanes más que a los indios, de suerte que se tenga consideración y distinción de las personas y que todos queden contentos". Adicionalmente, se incluyen las tierras donde los indios han mantenido sus labranzas, aunque estas se adjudican "sin embargo de cualesquier estancias proveídas y que se proveyeren a sus encomenderos o a otras personas particulares", e incluyendo "solo el sitio y tierra que ocupan las dichas labranzas y no más” (AGI, $A S$, ff. 4 v.-5 r.). Antes que garantizar la territorialidad ancestral de los nativos, las delimitaciones de resguardo se hicieron en función del lugar — geográfico y socioeconómicoasignado al indio dentro del orden colonial (Quiroga 193).

El examen de las visitas realizadas en la Vega de Supía en cada uno de estos dos ciclos arroja luz sobre la formación de territorialidades indígenas y ofrece elementos para futuros estudios comparativos.

\section{Visitando la Vega de Supía}

Situada en el costado noroccidental de la gobernación de Popayán, Anserma fue un área periférica y distante de los principales centros urbanos de Nueva Granada. Fue, al mismo tiempo, una región tempranamente colonizada debido a los ricos yacimientos minerales de Quiebralomo y Marmato, localizados en un área del extremo norte de la provincia conocida como la Vega de Supía (figura I). El intenso trabajo en estas minas contribuyó al drástico declive de 
la población nativa en el área, que se redujo de 40.000 habitantes a la llegada de los espańoles (I536-1539) a cerca de IO.000 en I559, y a un estimado de entre 800 y 1.500 en la década de $1580^{7}$.

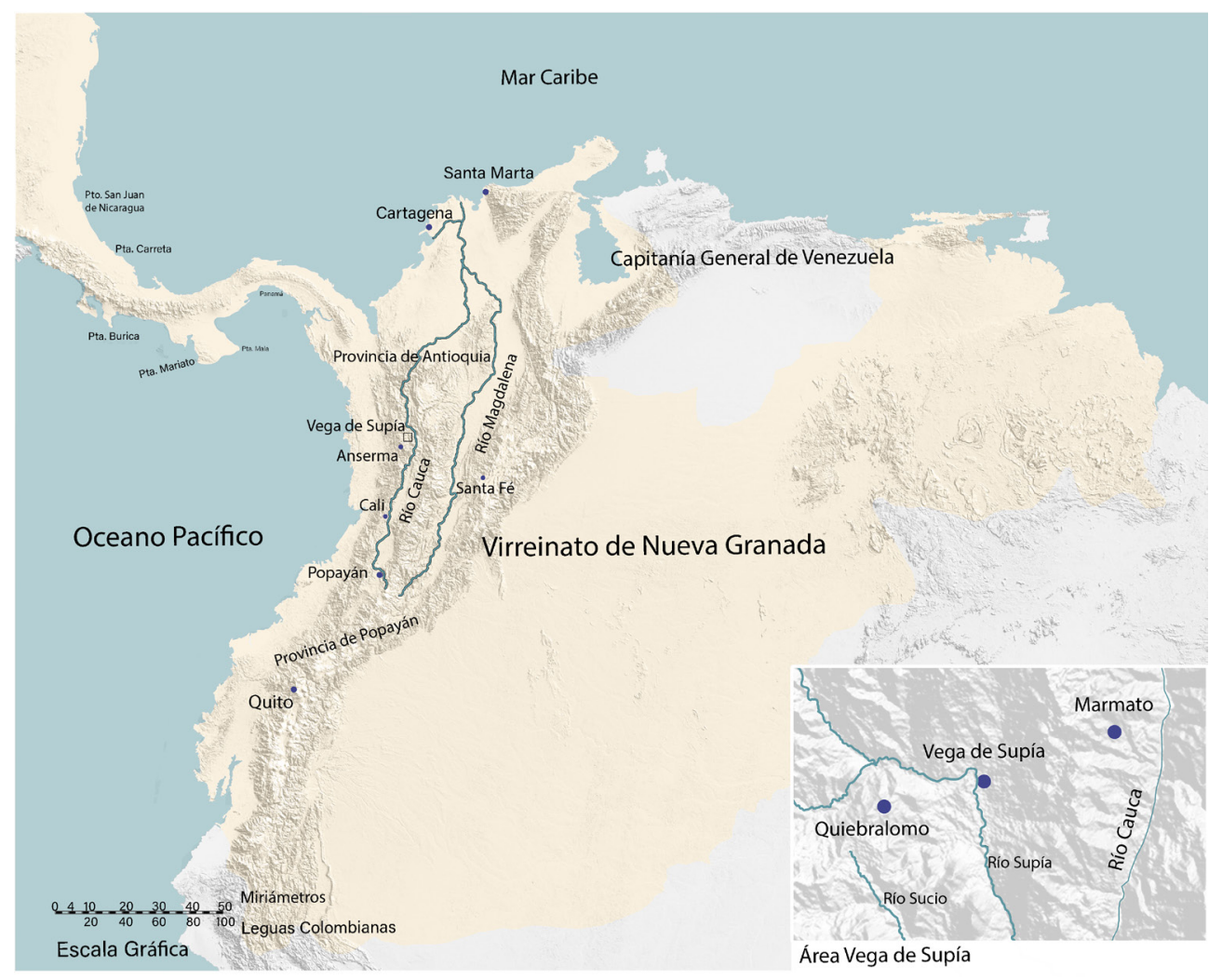

$\rightarrow$ FIGURA I.

Localización de la Vega de Supía

Fuente: elaborado por Daniel Vallejo con base en cartografías de Herrera, Popayán I2, II7)

En 1559, el oidor Tomás López Medel y el obispo Juan del Valle hicieron la primera visita a Anserma de la que existe registro, como parte de la visita a

7 Según fray Jerónimo de Escobar, a la llegada de los españoles la provincia de Anserma tenía más de 40.000 indios, de los que para la época en que escribía su informe (1582) solo quedaban cerca de 800 (300). En 1583, Francisco Guillén Chaparro reportó para toda la provincia "mil y quinientos indios escasos" (314). Por su parte, la cifra de 3.203 tributarios reportada por López Medel permitiría estimar entre 9.609 y 12.812 el total de la población nativa en Anserma para 1559, según se aplique un coeficiente de tres o cuatro indios por tributario (Jaramillo, "La población" 246). 
la gobernación de Popayán llevada a cabo entre 1558 y 1559. Esta visita fue ordenada directamente por Felipe II en respuesta a las denuncias presentadas por el obispo Juan del Valle sobre los abusos de los encomenderos y las quejas que estos últimos elevaron ante el Consejo de Indias en contra del obispo Del Valle, a quien acusaban de usurpar la jurisdicción civil al fijar una "tasa arbitraria" ante la ausencia de una tasación oficial (Friede, Vida 80).

La visita de 1559 se concentró en tasar los tributos y fiscalizar las condiciones de trabajo de los nativos. Las cuestiones territoriales no formaron parte de su agenda, como se infiere del hecho de que los visitadores no inspeccionaran "por vista de ojos" los lugares en los que habitaba la población indígena, "por ser alguna parte de la tierra muy fragosa y no poderse camynar a caballo y por no aver camynos y estar los indios derramados y no juntos como les esta mandado juntar y poblar en forma de pueblos de España” (López y Ares 238). Por tal motivo, López Medel requirió a los encomenderos para que acudieran a la ciudad de Anserma, en compañía de los "caciques" e "indios principales" de cada encomienda, a efectos de dar la información necesaria para tasar los tributos.

La tasación tuvo lugar en la ciudad de Anserma entre el 9 y el ro de junio de 1559. La transcripción de Ares Queija no revela cómo los visitadores obtuvieron la información necesaria para tasar los tributos; solo da cuenta de la tasa del tributo establecida en cada uno de los pueblos de la región de Anserma, el número de indios tributarios por pueblo, su estado civil y la encomienda a la que pertenecían. Para la región se contabilizaron un total de 3.203 tributarios desigualmente distribuidos en 27 encomiendas (tabla I).

$\bullet \quad$ TABLA I

Tributarios y encomenderos en Anserma, I559.

\begin{tabular}{|c|l|c|c|c|l|}
\multirow{2}{*}{\multicolumn{2}{|c|}{ Pueblo }} & \multicolumn{3}{c|}{ Tributarios } & \multirow{2}{*}{ Encomendero } \\
\cline { 3 - 6 } & & Casados & Solteros & Total & \\
\hline I & Guacayca & 74 & 40 & II 4 & Juan Moreta \\
\hline 2 & Unbria & 35 & I0 & 45 & Antonio de Pantoxa \\
\hline 3 & Chatapa & 65 & I2 & 77 & Alonso Gómez \\
\hline 4 & Opirama & I35 & 28 & I63 & Lazaro Martyn \\
\hline 5 & Piojo y Tucifra & 91 & I5 & I06 & Gaspar de Loaysa \\
\hline 6 & Zupinga & 50 & - & 50 & "De su Magestad" \\
\hline
\end{tabular}




\begin{tabular}{|c|c|c|c|c|c|}
\hline & \multirow{2}{*}{ Pueblo } & \multicolumn{3}{|c|}{ Tributarios } & \multirow{2}{*}{ Encomendero } \\
\hline & & Casados & Solteros & Total & \\
\hline 7 & Ypa & 28 & - & 28 & Pablo Pérez, el menor \\
\hline 8 & La Bieja & 70 & 20 & 90 & Andrés Pérez \\
\hline 9 & Mapura & 206 & 37 & 243 & Francisco Díaz \\
\hline IO & Tabuya & 164 & - & 164 & Francisco Díaz \\
\hline II & Guática & 160 & - & 160 & Gil Rengifo \\
\hline $\mathrm{I} 2$ & Yrra & 20 & 15 & 35 & Francisco Díaz \\
\hline 13 & Alonso & 29 & - & 29 & Bartolomé de la Rossa \\
\hline I 4 & Tuza y Apia & 42 & 20 & 62 & Gil Rengifo \\
\hline I5 & Andica & 78 & 25 & $\mathrm{IO} 3$ & Antonio de Sequera \\
\hline 16 & Chatapa & 108 & 29 & 137 & Miguel Dávila \\
\hline 17 & Aconchare & 85 & 17 & 102 & Miguel Dávila \\
\hline I8 & $\begin{array}{l}\text { Amaspache } \\
\text { (pueblo de Supía) }\end{array}$ & 55 & 37 & 92 & Gaspar de Loaysa \\
\hline 19 & Cumba & 138 & 76 & 214 & Antonio Sequera \\
\hline 20 & Apia & 150 & 36 & 186 & Florencio Serrano \\
\hline $2 \mathrm{I}$ & Pirsa & I29 & 100 & 229 & Gómez Hernández \\
\hline 22 & Supía & 175 & 80 & 255 & Lucas de Ávila \\
\hline 23 & Tutui & 56 & 17 & 73 & Antonio Pantoxa \\
\hline 24 & Apayache & 90 & 30 & 120 & Hernán Benítez \\
\hline 25 & Gorrones y Pito & 65 & 55 & 120 & Juan de Zúniga \\
\hline 26 & $\begin{array}{l}\text { Curumbí y } \\
\text { Gorrones }\end{array}$ & 125 & - & 125 & Bartolomé de la Rossa \\
\hline \multirow[t]{2}{*}{27} & Guarma & $4 \mathrm{I}$ & 40 & $8 \mathrm{I}$ & Hernando de Parada \\
\hline & Total & 2.464 & 739 & 3.203 & 18 \\
\hline
\end{tabular}

Nota: La zona en verde incluye los pueblos asentados en la "provincia de Anserma", mientras la azul corresponde a los pueblos de las "provincias de Pirza, Supía, Acumba y Gorrones de la ciudad de Anserma".

Fuente: López y Ares (24I-272) 
El tributo se tasó de forma colectiva, en función del tamaño de cada encomienda, representado en una determinada cantidad de mantas, alpargates, loza, sal, aves de corral y productos agrícolas. Por regla general, se prohibía el pago del tributo en oro para evitar el trabajo de los nativos en las minas. Sin embargo, López Medel y del Valle admitieron una excepción parcial a esta prohibición en las regiones de Anserma, Caramanta y Arma, al permitir a los indios cambiar la parte del tributo tasada en mantas de algodón por su valor en oro, lo que se explica por la importancia de la minería aurífera y la fuerte resistencia opuesta por los encomenderos de la región (López y Ares 264; Friede, Vida I2O-I3O, 250-257). La visita concluyó con la promulgación de unas "declaraciones" en las que se reiteraba a los encomenderos su obligación de proveer un cura doctrinero y recolectar los tributos sin exceder la tasación fijada; asimismo, se prohibía enviar a los nativos a trabajar en las minas, utilizarlos para servicios personales o para transportar carga a sus espaldas. Por último, se requería a los encomenderos "poblar a los dichos naturales y sus encomendados", a fin de ponerles "en toda policía espiritual y temporal” (López y Ares 27I).

Los registros de esta visita no informan sobre los patrones de asentamiento indígena. Aunque se menciona el término pueblo, no es claro si, por ejemplo, al referirse a los indios del "pueblo de Supía" se alude a su adscripción tribal, o a un grupo de nativos confiados al mismo encomendero, o a quienes habitaban un determinado asentamiento. Esto último es dudoso si se tiene en cuenta que López Medel y Del Valle declararon no haber hecho la inspección "por vista de ojos", debido a las dificultades de acceso y la dispersión de la población nativa. Adicionalmente, las ordenanzas expedidas al culminar la visita se referían a la obligación de los encomenderos de congregar a los indios en pueblos y dotarlos de un cura doctrinero, lo cual sugiere que la creación de pueblos de indios en Anserma no se había completado para la época de esta inspección. Es más probable que para entonces el término pueblo denotara los nuevos conjuntos sociopolíticos resultantes del reparto de la población nativa en encomiendas, antes que una localidad o asentamiento indígena (Quiroga 183). En efecto, como se aprecia en la tabla I, los indios Supía aparecen repartidos en dos "pueblos": Amaspache (pueblo de Supía), encomendado a Gaspar de Loaysa (n. I8) y Supía, encomendado a Lucas de Ávila (n. $\left.{ }^{\circ} 22\right)$. En definitiva, la visita de 1559 confirma que fueron el tributo y el trabajo, más que la tierra, los aspectos que concitaron la atención de las autoridades coloniales durante el primer ciclo de visitas. 
Aunque no se conocen registros de visitas practicadas a la Vega de Supía para finales del siglo XVI, al parecer se asignaron tierras de resguardo antes de 1627. En I594, los supías promovieron un pleito en defensa de las tierras de sus resguardos, de las que pretendía apoderarse la Iglesia para cobrarse unas deudas contraídas por su anterior encomendero. El capitán Hernán Benítez, uno de los testigos, declara que

desde que vino a esta tierra Pedro Holguín con comisión de la Real Audiencia [...] están poblados los dichos indios de Supía a donde ahora están; que puede hacer siete ocho años poco más o menos la cual dicha población está hecha a las cabeceras de la Vega porque antes estaban arrimados a las sierras. (AGN, $S C, R$, doc. 29, f. $8 \mathrm{I} 2$ r.)

Esto sugiere que hacia 1586-1587 se efectuó el poblamiento de los supías, acontecimiento que coincide con la visita hecha hacia 1585 por el gobernador de Popayán, Juan de Tuesta Salazar ${ }^{8}$. Asimismo, en la visita de 1627 se menciona haber inspeccionado "el resguardo de los indios de Supía la Baja que le dio Pedro de Alvarado, juez de tierras y estancias". De dicha asignación no se conservan más documentos que la referencia hecha por Espinosa Saravia, de la que se hace eco el novelista riosuceño Rómulo Cuesta, quien data el evento en I597 (AGN, $S C, V C$, doc. I, f. I22 r.; Cuesta II5).

La segunda visita a la región de Anserma de la que se conoce registro fue llevada a cabo entre febrero y abril de 1627 por el oidor Lesmes de Espinosa Saravia. En contraste con la visita de 1559, que documenta la presencia de I8 encomenderos y 3.203 indios tributarios, la de 1627 suministra un registro más rico y complejo del paisaje demográfico y social de una región en la que indios, negros esclavizados y españoles interactuaban en una sociedad dedicada a la minería, la agricultura y la cría de ganado. Mientras el número de encomenderos permanece igual en ambas visitas, el de indios tributarios disminuye drásticamente de 3.203 en 1559 a tan solo 538 en I627, IO5 de los cuales trabajaban en minas junto a 23I esclavos.

8 Friede analiza la visita de Tuesta Salazar a Cartago, pero no se ha estudiado para la región de Anserma (Los Quimbaya 137). 
$\rightarrow$ TABLA 2.

Población reportada en las visitas a la tierra efectuadas a la región de Anserma

\begin{tabular}{|c|c|c|}
\hline & 1559 & 1627 \\
\hline Encomenderos & $\mathrm{I} 8$ & $\mathrm{I} 8$ \\
\hline Indios tributarios & 3.203 & 538 \\
\hline Esclavos & ---- & 231 \\
\hline
\end{tabular}

Fuente: López y Ares; AGN, SC, VC, doc. I, f. 4I8 r.)

Como en 1559, el control sobre el tributo y el trabajo indígena fue un aspecto central de la visita de 1627. Espinosa Saravia se reunió con indios, encomenderos y señores de cuadrillas de esclavos; investigó los abusos cometidos contra los nativos, sancionó a los responsables y ejecutó y cobró las condenas impuestas; numeró a los indios, tasó los tributos y proveyó autos para el cobro del quinto real. Además, dispuso una reordenación del territorio que sentó las bases de las actuales divisiones territoriales y étnicas en la región de Anserma. Para el norte de la provincia, aquella se estructuró en torno a los pueblos de indios de La Montaña y La Vega, y los reales de minas de Quiebralomo y Marmato? .

En particular, la creación del pueblo de La Vega implicó un considerable traslado de poblaciones. A comienzos de I627, el sitio de La Vega (un valle situado alrededor del río Supía) se encontraba habitado por españoles, esclavos de minas e indios supías. El visitador ordenó a las I3 familias de españoles que allí residían trasladarse al valle de Pirza, situado a poco más de una legua de camino y habitado por los indios pirzas y umbras quienes, a su vez, serían trasladados a La Vega. Adicionalmente, dispuso que los indios sonsón y guaco, originarios de la provincia de Arma, fueran traídos desde su territorio ancestral al otro lado del río Cauca para ser reasentados en La Vega (figura 2). La tabla 3 muestra los diferentes grupos indígenas agrupados en la nueva población y la composición de cada uno de ellos.

9 Además, Espinosa Saravia dispuso concentrar la población nativa del sur de la provincia de Anserma en torno a los pueblos de Opirama, Tabuya, Guática Savana y Tusa (AGN, $S C, V C$, doc. I, ff. 312 r., 332 r.-335 v.; Caicedo, Cinco 32). 


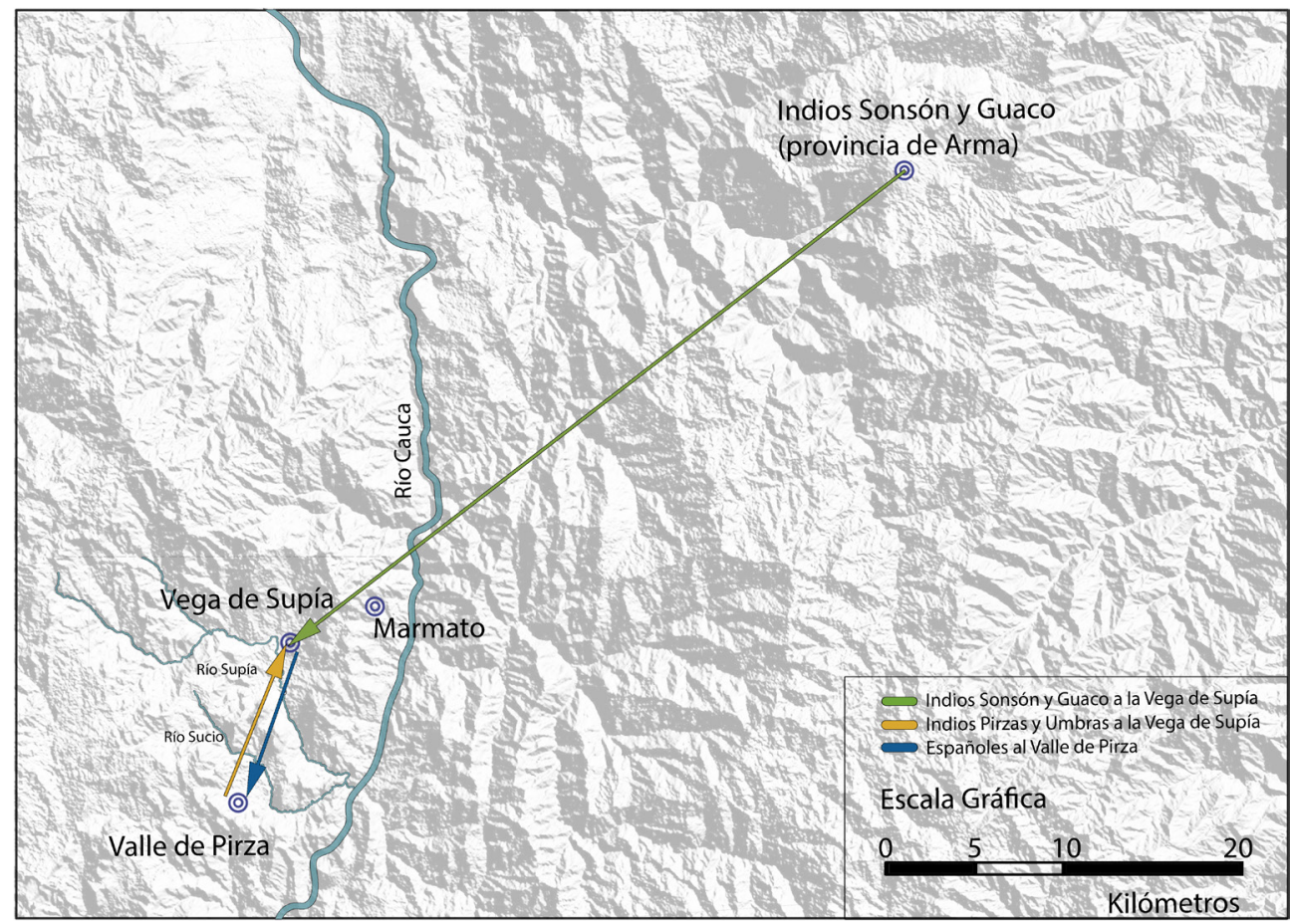

$\rightarrow$ FIGURA 2 .

Traslado de poblaciones desde y hacia la Vega de Supía

Fuente: elaborado por Daniel Vallejo, con base en AGN, SC, VC

Según el testimonio de Marcos, indio del repartimiento de Pirza, tanto los de su pueblo como los indios de Supía la Baja y la Alta son todos "ladinos y hablan la lengua española” y de tiempo atrás mantenían comunicación y comercio. Por su parte, los indios de Sonsón también habían mantenido contacto con los de Anserma, pues entre sus nueve indios forasteros figuran naturales de los pueblos de Pirza y Opirama (Agn, $S C$, VC, doc. 2, ff. 538 v.-540 v.; doc. I6, ff. 9 I4 r.-9I7 v.). 
$\leftrightarrow$ TABLA 3 .

Indios congregados en el pueblo de La Vega

\begin{tabular}{|c|c|c|c|}
\hline Pueblo & Encomendero & Número de indios & $\begin{array}{l}\text { Total indios } \\
\text { por pueblo }\end{array}$ \\
\hline $\begin{array}{l}\text { Supía } \\
\text { la Alta y } \\
\text { Arquía }\end{array}$ & Lucas de Salazar & $\begin{array}{l}23 \text { útiles } \\
\text { I cacique } \\
4 \text { reservados } \\
7 \text { ausentes } \\
80 \text { mujeres, hijos y familia }\end{array}$ & IIS \\
\hline $\begin{array}{l}\text { Supía } \\
\text { La Baja }\end{array}$ & Manuel Barbosa & $\begin{array}{l}29 \text { útiles } \\
\text { I gobernador } \\
5 \text { reservados } \\
6 \text { ausentes } \\
74 \text { mujeres, hijos y familia }\end{array}$ & IIS \\
\hline Umbría & Garciperez & $\begin{array}{l}3 \text { útiles } \\
4 \text { ausentes } \\
9 \text { mujeres, hijos y familia }\end{array}$ & 16 \\
\hline Pirza & María Redondo & $\begin{array}{l}23 \text { útiles } \\
\text { I cacique } \\
3 \text { reservados } \\
6 \text { ausentes } \\
\text { I04 mujeres, hijos y familia }\end{array}$ & $\mathrm{I} 37$ \\
\hline Sonsón & $\begin{array}{l}\text { De su Majestad, } \\
\text { administra Francisco } \\
\text { Llorente }\end{array}$ & $\begin{array}{l}\text { I I útiles } \\
\text { I reservado } \\
\text { I ausente } \\
54 \text { mujeres, hijos y familia }\end{array}$ & 67 \\
\hline Guaco & Mateo de Castrellón & $\begin{array}{l}3 \text { útiles } \\
8 \text { mujeres, hijos y familia }\end{array}$ & II \\
\hline \multicolumn{3}{|l|}{ Total } & $46 I$ \\
\hline
\end{tabular}

Fuente: AGN, SC, VC, doc. I, ff. 326, 335 V.-336 r.

Para el tiempo de la visita, Juan de Mesa Betanzos, cura de Marmato, asistía de manera esporádica a los indios de La Montaña, Supía y Pirza, en capillas de caña y paja construidas en sus asientos, lo que sugiere que en aquel entonces se había iniciado el proceso de reducciones. Los pirzas detallan que el padre Mesa Betanzos los asistía "un mes cada año" y que "por haber estado 
tanto tiempo sin padre han muerto sin confesión algunos indios e indias". Para remediar esta situación, Espinosa Saravia dejó establecidas las doctrinas de La Montaña, La Vega, Quiebralomo y Marmato. Los indios reducidos a la nueva población de La Vega estarían bajo la vigilancia espiritual de un sacerdote encargado también de asistir a sesenta esclavos que laboraban en las minas de La Vega de Supía y a trece familias de españoles, aunque a estos últimos en iglesias separadas a fin de hacer efectiva la separación entre las dos repúblicas. Así, el cura ostentaría la doble condición de doctrinero de indios y cura de españoles (AGN, $S C, V C$, doc. I, ff. 62 r. -65 r.; doc. 2, f. 538 r.).

El visitador plasmó la traza del nuevo pueblo en una pintura, y a través de ella explicó a los indios cómo sería su población:

Y se les dijo que esta casa y bohío es por ahora buena para iglesia, y delante de ella a la parte de arriba se ha de hacer una plaza grande cuadrada y aposentos del padre, y en su contorno de la plaza se ha de hacer el poblado por cuatro partes: Supía la Baja, Supía la Alta, Pirza y Sonsón [...] Luego los dichos indios por mandado de dicho señor oidor visitador cortaron y levantaron los bareques del bohío para que se haga la iglesia y el altar, y que se traiga la campana de Supía la Baja a la dicha nueva iglesia. (AGN, $S C, V C$, doc. I, f. I22)

Además de la traza, Espinosa Saravia demarcó los resguardos, que fueron garantizados de manera separada a los pueblos congregados en La Vega, aunque las tierras del llano se destinaron a ejido común para las bestias y ganados de los cuatro repartimientos. En lugar de medir las tierras conforme a lo establecido en la relación de Ibarra de 1593 , los límites de cada resguardo se fijaron a partir de criterios de posesión ancestral (en el caso de los supías) y demarcaciones naturales o linderos (en el caso de los llegados de Pirza y Sonsón):

A los indios de Sonsón se le señala la estancia de Miguel Morillo Labrador, lo que [...] incluye desde la quebrada que llaman de Gregorio de Rodas corriendo dicha quebrada arriba hasta la ceja del monte, todo lo que comprende la loma hasta la vertiente del potrero de Supía la Baja y hasta la quebrada de la peńa colorada, en esta encima de la loma, para que las repartan entre sí y sus familias en conformidad de sus costumbres.

A los indios de Supía la Alta y Arquía les da, señala, y adjudica todas las tierras que tenían y poseían y han gozado y poseído antes de esta reducción y población han tenido por términos y resguardos, y se les ampara en ellos y en sus huertas, cercados y plantares, yucales 
y árboles frutales. Y se les deja todo ello, y se declara que el sitio donde el encomendero don Lucas de Salazar ha tenido y tienen sus aposentos se declara quedar anejo a los dichos resguardos para que el encomendero que es o fuere de estos indios tenga sus aposentos sin que pueda acercarse más a la nueva población en que se les ampara.

A los indios de Supia la Baja les deja, ampara y adjudica en todas las tierras y resguardos y sus términos que han tenido, gozado y poseído hasta el día de esta reducción hasta la roza que actualmente tiene el cacique don Gaspar, y de allí corriendo la loma arriba atravesando el camino real que va al río Grande hasta dar en la loma de Cosumbí, línea recta hasta la cumbre hacia donde nace el sol. Y asimismo les ampara en los sitios de su pueblo viejo, casa, huertas y cercas, platanares yucales y batatales [...]

A los indios del pueblo de Pirsa se les da y señala desde la dicha roza del cacique don Gaspar que esta linde con la estancia de Cristóbal Sánchez Hellín y toda la tierra que hay hacia la sierra a las espaldas de esta dicha estancia de Cristóbal Sánchez Hellín y Francisco Romero, que quedan por estancias de pan y ganado menor conforme a la vista de ojos [...] y así mismo les ampara a los dichos indios en el sitio y asiento de su pueblo viejo de Pirza y en sus huertas, cercados y plantanares, yucales y batatales [...][...] y los indios del pueblo de Umbría van comprehendidos con esos dichos Pirzas en las dichas tierras y resguardos. (AGN, $S C, V C$, doc. I, ff. I4O r.-I4I v.)

Por último, el visitador expidió una serie de ordenanzas en las que prohibía trasladar a los indios de los pueblos a los que fueron reducidos sin previa autorización de la Real Audiencia, además de otras medidas para hacer efectivo el ordenamiento territorial dispuesto en la visita (AGN, $S C$, VC, doc. I, ff. 312-322).

El reasentamiento de población nativa y la distribución de resguardos, efectuada en la visita de 1627 , estimularon un proceso de reconfiguración territorial y étnica que aún no ha sido estudiado lo suficiente. Historiadores e intelectuales indígenas afirman que la actual comunidad indígena de San Lorenzo es descendiente de los sonsones y demás indios traídos por Espinosa Saravia desde la provincia de Arma (Zuluaga 39; Tapasco), pero la información demográfica disponible pone en duda esta hipótesis. Los indios naturales del pueblo de Sonsón que fueron asentados en La Vega en I627 figuran con los apellidos Sonsón, Moraga y Criollo. En un censo realizado en 1703 a los cuatro 
partidos entonces pertenecientes al pueblo de San Lesmes de Supía: Supía la Baja, Pirza, Pipintá y Sonsón, en este último solo figuran cuatro indios, todos ausentes, con los apellidos Sonsón, Beltrán y Tumbo. En 1706 se efectuó una nueva numeración del pueblo de San Lesmes de Supía, que esta vez solo incluyó dos partidos: Supía y Pirza (este último incluyó los indios de Pipintá). El partido de Sonsón ya no figura como agregado a este pueblo, lo que sugiere que para entonces se daba por extinto. En 1706 figuran en el partido de Supía tres indios de apellido Sonsón, ausentes de tiempo atrás en Antioquia. A su vez, en las numeraciones de 1703 y 1706 se menciona el pueblo de San Lorenzo como un "pueblo de indios de la jurisdicción" en el que vivían o con cuyas mujeres estaban casados algunos de los indios de los partidos de Supía y de Pirza, sin que aparezca ninguna asociación expresa entre dicho pueblo y los indios de Sonsón.

La primera numeración del pueblo de San Lorenzo de que se tiene noticia data de 1729. Consta de un total 87 personas cuyos apellidos también aparecen en las listas censales de otros partidos de la zona. La única coincidencia entre la lista de naturales de Sonsón de I627 y la de San Lorenzo en 1729 es el apellido Criollo (tabla 4). Para 1729 el apellido Sonsón tan solo figura en dos indios listados en el partido de Cañamomo, que son registrados como oriundos de Mariquita (tabla 5). Esto desvirtúa la tesis de la continuidad entre los pueblos de Sonsón y San Lorenzo. Un documento presentado en 1758 por los indios de Cañamomo dentro del pleito con los supías sugiere una hipótesis alternativa, al señalar que la parcialidad de Supía la Alta "se mantiene hoy con el título de San Lorenzo" (AGN, $S C, R$, doc. 25 , f. 619 r.). Aunque la evidencia analizada no es suficiente para reconstruir la génesis del pueblo de San Lorenzo, ella sugiere que pudo resultar de la agrupación entre varias familias indígenas de distintos partidos, incluidos los de la encomienda de Supía la Alta.

Entre tanto, los indios pirzas y umbras, a quienes se les asignó un mismo resguardo, se mezclaron en el partido de Pirza que, tras acoger a los Cumba y otras familias procedentes del sur de Anserma, en las primeras décadas del siglo Xviı pasó a llamarse Cañamomo-Lomaprieta (o simplemente Cañamomo). Los indios de Lomaprieta aparecen por primera vez en los archivos en un documento de I70I en el que el protector de naturales de la Real Audiencia se opone al traslado de estos indios a tierras de Supía La Baja, dispuesto por el teniente de alcalde de la ciudad de Anserma. El protector dice que "se compone dicho pueblo de Lomaprieta de dos parcialidades, la una llamada Pirza y la otra Cumba y todos se llaman Curicamayos" y explica que el sitio de Lomaprieta, al 
$\rightarrow \quad$ TABLA 4 .

Apellidos en los censos de Sonsón y San Lorenzo

\begin{tabular}{|c|c|c|c|}
\hline \multirow{2}{*}{ Apellido } & \multicolumn{2}{|c|}{ Sonsón } & \multirow{2}{*}{$\begin{array}{c}\text { San Lorenzo } \\
1729\end{array}$} \\
\hline & 1627 & 1703 & \\
\hline Sonsón & 37 & I & \\
\hline Moraga & 2 & & \\
\hline Criollo & 2 & & 4 \\
\hline Beltrán & & I & \\
\hline Tumbo & & 2 & \\
\hline Betancur & & & 2 \\
\hline Motato & & & IO \\
\hline Tapasco & & & 8 \\
\hline Batero & & & 7 \\
\hline De la Cruz & & & 5 \\
\hline Andica & & & 5 \\
\hline Rueda & & & I \\
\hline Gañán & & & I 4 \\
\hline De Ávila & & & 6 \\
\hline Blandón & & & I \\
\hline Ancho & & & 4 \\
\hline Lanteros & & & 3 \\
\hline Guapacha & & & I \\
\hline Rivera & & & 7 \\
\hline Tamayo & & & 5 \\
\hline Cumba & & & I \\
\hline Lengua & & & I \\
\hline Calima & & & I \\
\hline
\end{tabular}

Fuente: AGN, SC, VC, doc. I6, ff. 9I4 r.-9I7 V.; AGN, SC, R, doc. 27, f. 759; ACC, Col, ff. II V.-I3 V. 
que pide sean retornados, dista media legua del real de minas de Quiebralomo ${ }^{\text {Io }}$. En una petición presentada en 1703 por los indios del pueblo de San Lesmes de Supía, que entonces congregaba los partidos de Supía La Baja, Pirza, Pipintá y Sonsón, estos manifiestan:

[...] los indios de Lomaprieta no se deben mirar como de este partido, porque distan de este pueblo legua y media [...] porque los dichos indios no pasan de cinco, no tienen pueblo en el dicho sitio ni nunca lo han tenido, sino solo sus labranzas y estancias [...] [las cuales distan] un cuarto de legua del dicho Llano de Supía. (AGN, $S C, R$, doc. 27, f. 752 r.)

Sin embargo, en la numeración hecha el mismo año, un total de seis de las veinte familias del partido de Pirza censadas como presentes figuran como residentes en Lomaprieta ${ }^{\text {II }}$. En 1706 , algunas de estas familias aparecen como residentes en Quiebralomo. Esto sugiere un paulatino desplazamiento de los pirzas desde el pueblo de San Lesmes de Supía hacia el sitio de Lomaprieta y la doctrina de Quiebralomo, situados en dirección a su antiguo territorio en el valle de Pirza, desplazamiento que, como se explicará más adelante, se relaciona con la ocupación de las tierras del llano de Supía con ganados de españoles.

En I72I, los indios de La Montańa, con el apoyo de su doctrinero, comenzaron a asentarse en el sitio de Riosucio (cerca de la actual cabecera de Riosucio) y solicitaron permiso para instalar allí su pueblo argumentando que el sitio apenas estaba habitado por diez indios forasteros. Los de CańamomoLomaprieta, quienes ocupaban este sitio con sus labranzas, pidieron al cura de Quiebralomo certificar el número de indios de ese partido, para así probar sus derechos sobre el sitio en disputa. El cura certificó 79 indios que concurrían a la doctrina y contribuían al sostenimiento de la iglesia y del real de minas (ACCL; M. E. Escobar). Esta numeración, al igual que la realizada en I729, revela que la familia Lengua, tronco principal del antiguo partido de Pirza, pasa al de Cañamomo-Lomaprieta, mientras que el apellido Pirza desaparece. A su vez,

Io Esta petición forma parte de los documentos protocolizados en la escritura 263 de 1903 de la notaría de Riosucio, que contiene los títulos de la parcialidad de Cañamomo-Lomaprieta (ACCL). La expresión curicamayo significa indios de minas (Caicedo, Cinco 44).

II Para 1703 , el partido de Pirza registra un total de 66 personas, 47 de ellas presentes ( 13 tributarios, 2 reservados, 9 indias, 23 chinos y chinas) y 19 ausentes (Io tributarios, 7 indias, 2 chinos y chinas). En la numeración de 1706 se contaron " 87 cabezas, en que se incluyen 13 tributarios presentes, 5 tributarios ausentes en distintas jurisdicciones, 2 reservados y 67 indias, chinas y muchachos, con algunas cabezas ausentes" (AGN, $S C, R$, doc. 27 , ff. 756 v. -758 v. y 769 r.). 
en estas numeraciones aparecen nuevos apellidos: Cumba, Blandón, Tapasco, Guarcaya, Tamayo y Tabuya, entre otros, lo que evidencia la integración de este partido con familias procedentes del sur de la provincia de Anserma ${ }^{12}$.

$\rightarrow$ TABLA 5 .

Apellidos en los censos de Pirza y Cañamomo-Lomaprieta

\begin{tabular}{|c|c|c|c|c|}
\hline \multirow[t]{2}{*}{ Apellido } & \multicolumn{2}{|c|}{ Pirzas } & \multicolumn{2}{|c|}{$\begin{array}{l}\text { Cañamomo- } \\
\text { Lomaprieta }\end{array}$} \\
\hline & 1703 & 1706 & 1721 & 1729 \\
\hline Lengua & 26 & 32 & 17 & 34 \\
\hline Pirza & 3 & 2 & & \\
\hline Santiago & 4 & 4 & & \\
\hline Gómez & I & 7 & & \\
\hline Largo & I & I & & \\
\hline Popayán (forastero) & 3 & 2 & & \\
\hline Grandes & I & & & \\
\hline Gañán & 2 & & & I \\
\hline Batero (de La Montaña) & 3 & I & I & 2 \\
\hline Ancho & 2 & 2 & I & I \\
\hline Silvestre & I & & & \\
\hline Umbría & I & & & I \\
\hline Velásquez & & 8 & & \\
\hline Tronera & & 3 & & \\
\hline Choré (de Supía) & & 9 & & \\
\hline Bachiller (de Sopinga) & & 5 & & \\
\hline Pipintá & & 8 & & \\
\hline
\end{tabular}

12 Para I721, el partido de Cañamomo-Lomaprieta se componía de 70 indios (I 4 tributarios, 5 reservados, 5 I mujeres y chusma) y 9 agregados. En 1729 se registran Ior naturales (un alcalde, I7 tributarios, un ausente, 4 reservados, 3 I mujeres, 47 chinos y chinas). 


\begin{tabular}{|c|c|c|c|c|}
\hline \multirow[t]{2}{*}{ Apellido } & \multicolumn{2}{|c|}{ Pirzas } & \multicolumn{2}{|c|}{$\begin{array}{l}\text { Cañamomo- } \\
\text { Lomaprieta }\end{array}$} \\
\hline & 1703 & 1706 & 1721 & 1729 \\
\hline Quebrada & & I & & \\
\hline Tamayo & & & 3 & 2 \\
\hline Tabuya & & & 5 & 9 \\
\hline Cumba & & & 23 & 13 \\
\hline Blandón & & & 3 & IO \\
\hline Guarcaya & & & 7 & 8 \\
\hline Tapasco & & & $\mathrm{I} 2$ & 4 \\
\hline Guasca & & & I & \\
\hline Beltrán & & & 3 & 3 \\
\hline Motato & & & 2 & 5 \\
\hline De la Cruz & & & I & I \\
\hline Boxcaya & & & & I \\
\hline Bueno & & & & I \\
\hline Fitata & & & & I \\
\hline Sonsón (de Mariquita) & & & & 2 \\
\hline
\end{tabular}

Fuente: AGN, SC, R., doc. 27, ff. 756 V.-758 v.; ACC, Col, ff. IO v.-II r.; ACCL, E.

Respecto de los supías, el censo de 1703 registra un total de 85 personas (43 presentes y 42 ausentes), que en 1706 se incrementa a II7 (95 presentes, 22 ausentes) y en 1729 a I $28^{13}$. Este incremento resulta de la agregación de nuevos miembros de diversa procedencia, más que del crecimiento de las familias previamente registradas, como lo sugiere la presencia de doce nuevos apellidos en

I3 Las 85 personas registradas en total para el partido de Supía en 1703 corresponden a 43 presentes (Io tributarios, 4 reservados, 9 indias, 20 chinos y chinas) y 42 ausentes ( 13 tributarios, 4 reservados, 9 indias, 16 chinos y chinas). En 1706 , la cifra de 117 corresponde a 95 presentes (17 tributarios, 7 reservados, 30 indias, $4 \mathrm{I}$ chinos y chinas) y 22 ausentes (Io tributarios, 9 indias, 3 chinos y chinas). Las 128 registradas en 1729 corresponden a un alcalde, I 8 tributarios, 8 reservados, 34 mujeres y 67 chinos y chinas. 
I706 y de veintidós más en I729. En este periodo desaparecen algunos apellidos tradicionales como Amaspacha y Supía, aunque se mantienen otros como Ancho, Largo, Chore y Umbría. Este último evidencia que los umbras, quienes en I627 fueron agrupados con los pirza en el mismo resguardo, no se integraron al partido de Pirza (luego Cañamomo-Lomaprieta) sino al de Supía. Los nuevos apellidos en los censos de 1706 y 1729 sugieren la llegada al pueblo de Supía de indios procedentes de otros partidos de la zona. Asimismo, la presencia de apellidos no indígenas, sumada a la mención de matrimonios de algunos indios con mestizos y mulatos, revela un proceso de mestizaje más acentuado que el observado en San Lorenzo y Cańamomo. De otro lado, la división entre las encomiendas de Supía La Alta y la Baja paulatinamente desaparece de los registros. En el censo de 1703 se precisa que el partido de Supía corresponde a Supía la Baja y aunque se menciona Supía La Alta como el partido al que pertenecen algunas de las personas registradas, no hay un listado censal de este último ni se menciona en los listados de 1706 y 1729 (tabla 6).

$\leftrightarrow$ TABLA 6.

Apellidos en los censos de Supía

\begin{tabular}{|l|c|c|c|}
\hline \multicolumn{1}{|c|}{ Apellido } & 1703 & 1706 & 1729 \\
\hline Amaspacha & 2 & & \\
\hline Herrero & 2 & & 8 \\
\hline Ancho & I3 & I3 & I \\
\hline De la Rosa & I & I & I I \\
\hline Anduquima o Anduquia & I & 6 & 7 \\
\hline Largo & 5 & I & I \\
\hline Silvestre & 2 & I & \\
\hline Supía & I & 8 & I \\
\hline Botas o Bocta & II & I & \\
\hline Chori o Chore & I & & \\
\hline Montaña & I & & \\
\hline Moscas & I & & \\
\hline Barrios & & & \\
\hline
\end{tabular}




\begin{tabular}{|c|c|c|c|}
\hline Apellido & 1703 & 1706 & 1729 \\
\hline Cota & I & 3 & \\
\hline Umbría & 8 & 17 & 7 \\
\hline Blandón & 3 & & \\
\hline Bachiller (de Sopinga) & 4 & 4 & 7 \\
\hline Guapacha & & I & \\
\hline Gala & & I & \\
\hline Romero & & 3 & 3 \\
\hline Rodríguez (forastero) & & I & \\
\hline Sonsón (ausentes en Antioquia) & & 3 & \\
\hline Chachurra o Chaurra (de Guática) & & 2 & 6 \\
\hline Nungazeldo & & I & \\
\hline Uchima o Utima (de Savana) & & I & 2 \\
\hline Tronera & & 2 & 3 \\
\hline Gañán & & 2 & \\
\hline Grande & & I & 4 \\
\hline Popayán (forastero) & & 2 & \\
\hline Quebrada & & & 4 \\
\hline Gómez & & & 8 \\
\hline De los Santos (mulata) & & & I \\
\hline Tavima & & & 4 \\
\hline Lengua & & & 8 \\
\hline Batero (La Montaña) & & & I5 \\
\hline De Ávila & & & 3 \\
\hline Velásquez & & & I \\
\hline Porras & & & 2 \\
\hline Ruiz & & & 3 \\
\hline González & & & 5 \\
\hline
\end{tabular}




\begin{tabular}{|l|l|c|c|}
\hline \multicolumn{1}{|c|}{ Apellido } & 1703 & 1706 & 1729 \\
\hline De los Ríos & & & I \\
\hline Echalarga & & & 2 \\
\hline Villada (de San Antonio) & & & I \\
\hline De la Rosa Gallegos (mestiza) & & & I \\
\hline Inga & & & IO \\
\hline Ladino (La Montaña) & & & I \\
\hline Morales & & & 3 \\
\hline Mozo & & & I \\
\hline López & & & 2 \\
\hline Tabuya & & & 2 \\
\hline Pipintá & & & \\
\hline
\end{tabular}

Fuente: AGN, SC, R., doc. 27, ff. 754 r. -756 r.; ACC, Col, ff. 7 r.-9 v.

En definitiva, el proyecto de reducir supías, pirzas, umbras y sonsones al pueblo de indios de La Vega no se ajustó en todo a lo dispuesto por Espinosa Saravia. Aunque el pueblo de San Lesmes de Supía llegó a existir y a congregar los partidos de Supía la Baja, Pirza, Sonsón y Pipintá (este último agregado al real de minas de Marmato en 1627), para 1729 los indios de los emergentes partidos de San Lorenzo y Cañamomo-Lomaprieta se encontraban bajo la jurisdicción del cura de Quiebralomo, mientras que en el curato de La Vega solo quedaban los supías. De acuerdo con lo previsto por el visitador, se construyeron dos iglesias en La Vega, la del pueblo de indios de Supía y la de Nuestra Señora Candelaria de Sevilla, en un intento de hacer efectiva la separación entre las dos repúblicas. Con todo, un alto número de españoles tenían sus tierras y asientos en la Vega de Supía.

La dispersión no impedía la interacción entre la población nativa, a través de matrimonios entre indios de los distintos pueblos asentados en La Vega, de otros partidos de Anserma y de zonas como Antioquia, Buga, Mariquita o Popayán. Asimismo, el desplazamiento de los indios de la Vega de Supía hacia esas y otras regiones, demuestra la movilidad de la población indígena por fuera de los espacios a los que había sido reducida. Aunque la concentración en un 
mismo espacio urbano no se ajustó a lo previsto por el visitador, su distribución de resguardos marcó la pauta para definir futuros conflictos territoriales.

\section{Lesmes revisitado. La disputa entre los indios de Cañamomo y Supía en 1757}

Desde finales del siglo Xvir, los españoles que tenían estancias contiguas a los resguardos habían ocupado las tierras del llano de Supía con ganado, lo que motivó a varias familias indígenas a desertar del pueblo. Los supías acudieron a Anserma con sus "títulos y resguardos" para demandar justicia, sin lograr "otro fruto que confundirnos y perdernos dichos títulos y resguardos hasta lo presente, dejándonos indefensos”, según relató su alcalde, Pedro Bachiller, en 1749. Este explicó que, persuadidos por su cura, aceptaran arrendar las tierras a los españoles, a fin de controlar la entrada de ganado y obtener ingresos para sostener su iglesia. Con el argumento de que se trataba de tierras vacas, el español Manuel de la Peña Minaya obtuvo en 1697 merced sobre las tierras del llano y, a través de composiciones, logró apropiarse de otras tierras adyacentes. Entre 1709 y I7I5 sus herederos vendieron estas tierras a las iglesias, que se lucraron de ellas hasta que, luego de un largo pleito, el virrey ordenó amparar a los indios de Supía en la posesión del llano de Supía, donde fueron restablecidos en 1750 por Francisco Antonio López de Vicuña, alcalde ordinario de Anserma (AGN, $S C, R$, docs. 27 y 32 ).

Los cañamomos descendían de las familias del antiguo partido de Pirza que, presionados por la invasión de sus tierras con ganados de españoles, se habían desplazado desde el pueblo de La Vega hacia las montañas situadas en dirección al valle de Pirza. Luego de disputar a los indios de La Montaña la posesión del sitio de Riosucio, los cañamomos sufrieron un duro revés cuando en 175I la Real Audiencia decidió el pleito en favor de La Montaña. Los cañamomos quedaron entonces confinados en el sitio de Lomaprieta o Cańamomo, un área montańosa a medio camino entre los valles de Pirza y Supía, fuera del alcance de las autoridades coloniales y sustraídos del pago del tributo. Para I757, estos sumaban un total de 55 personas (Io tributarios, I5 indias, II chinos y 19 chinas), que vivían en "ocho casas dispersas unas de otras" (AGN, $S C, R$, doc. 25 , f. 646 v.). 
Ese año, Juan Blandón, alcalde de Cañamomo, reclamó la restitución de las tierras que Lesmes de Espinosa Saravia había otorgado a sus ancestros como resguardo en La Vega. Junto a la restitución de su resguardo, reclamaba el dinero que la Iglesia había recibido por el alquiler de sus tierras, con el cual debía fundarse una caja de comunidad destinada al pago de los tributos que adeudaban a la Corona. Blandón se apoyaba en la memoria de la visita de Lesmes de Espinosa para fundamentar su pedido:

Nosotros teníamos nuestro Pueblo, en el Valle de Pirsa y por resguardos de tierras todo el dicho valle de donde nos sacó el señor oidor Don Lesmes de Espinosa Sarabia visitador general de esta Provincia para las fundaciones de Pueblos, y repartimientos de sus resguardos y nos fundó en las cabeceras de esta Vega, [...] en cuya posesión nos mantuvimos hasta que ocultándonos nuestros títulos nos las quitaron injustamente y se las dieron a las Iglesias.

Invocó además el triunfo legal obtenido por los supías en 1750, el cual, a juicio de Blandón, también beneficiaba a los cańamomos:

A pedimento de los Naturales del Pueblo de Supia en vista de las Ordenanzas de dicho Sr. Oidor Visitador [...] el año de cincuenta que pudieron hallar los instrumentos el excelentísimo Sr. Virrey de este reino declaro ser nuestro dicho Llano, y en virtud de despacho de Su excelencia, Don Francisco Antonio López de Vicuña, siendo alcalde ordinario, nos dio posesión y después en otro despacho manda su excelencia que se nos ampare en dicha asignación. (AGN, $S C, R$, doc. 25, ff. 590 r.-590 v.) $)^{14}$

Entre tanto, Miguel Batero, Bonifacio de la Cruz, Dionicio Chore y Pedro Bachiller, los dos primeros alcaldes y los dos últimos regidores del pueblo de Supía, argumentaban que los Cañamomo "no tienen derecho ya a estas tierras pues el que tenían o en algún tiempo pudieron tener lo han perdido”, por haber desertado de su pueblo hacía más de ochenta años, lo que facilitó a los blancos apoderarse de sus tierras. Señalaron además que, de haber reconocido estas tierras como suyas, no habrían tenido pleito con el pueblo de La Montaña, censurando el talante litigioso de los cańamomos que les ha dejado "atrasados y pobres" porque "mientras pleiteamos nosotros no podemos trabajar, y

I4 Luis Javier Caicedo publica apartes de este pleito en una recopilación de documentos inéditos sobre Riosucio ("Transcripción” 204). 
nuestro caudal es el trabajo de nuestras personas para con él mantenernos y pagar tributos". A continuación, sin embargo, defendieron el derecho exclusivo de los indios de Supía sobre las tierras del llano porque fueron ellos quienes las recuperaron "a costa de muchos trabajos, muchos pasos, y muchos pesos", e incluso "a costa de la vida del regidor Mariano que murió en ese camino de Santafé por defender el pleito, y acomodar a los de nuestro pueblo en dicho Llano”. Finalmente, los supías rechazaron la apelación a la identidad grupal que invocaban los cañamomos, basada en su pertenencia, junto con los supías, al pueblo erigido por el visitador en I627, con fundamento en la cual se sentían partícipes de la victoria legal obtenida por los supías en 1750. Estos últimos, en cambio, enfatizaron que "a quienes se les dio la posesión por Don Francisco de Vicuña [...] fue a nosotros, que habíamos vencido, y no a los Cañamomos, ni otros ningunos, por lo que sólo nosotros quedamos dueños del dicho Llano" (AGN, $S C, R$, doc. 25, ff. 59I v.-592 v.).

En esta victoria legal de los supías fue decisiva la intervención de Simón Pablo Moreno de la Cruz, miembro de una poderosa familia propietaria de minas y cuadrillas de esclavos en Marmato, cuyo ascenso ejemplificó la transición de la encomienda a la hacienda minera en la región (Gärtner 72). Cuando fue teniente gobernador y corregidor de naturales, Moreno de la Cruz ayudó a los supías a recuperar los títulos con los que lograron el amparo de las tierras del llano en 1750. En 1757, ya como alcalde ordinario de Anserma, respaldó a los cañamomos en su pleito contra los supías, quienes advertían que "el señor Don Simón Moreno [...] siendo Teniente nos ayudó a quitar nuestras tierras estando en posesión de las Iglesias; ahora ayuda a los Cañamomos para que nos las quiten a nosotros; y mañana siendo de ellos ayudará a otros para que se las quiten a ellos" (AGN, $S C, R$, doc. 25, f. 626 r.).

Por su parte, el corregidor de naturales, Francisco Javier de Borja, expresaba abiertamente su animadversión hacia los indios, a quienes consideraba "malos, nobeleros y quimeristas; y estos de Cañamomo son más malos que todos los demás; toda la vida la pasan pleitiando y vagabundos, no pagan tributos muchos años ha”. A la vez que se quejaba del excesivo litigio de los nativos y del uso de la memoria de la visita de Lesmes para fundamentar sus quejas, el corregidor sugería utilizar el arreglo territorial dispuesto por el visitador para zanjar la disputa entre cañamomos y supías:

Estos indios y todos los demás de este distrito se valen para sus pedimentos de las ordenanzas del Sr. Don Lesmes; ¿pues por qué estas no han de ser la guía para arreglarlos a vivir donde dicho sr. visitador los 
puso y dejó, para que no haya pleitos? El Sr Don Lesmes dejó estos indios en el Pueblo de Supía este es su propio pueblo; ¿pues por qué no se han de arreglar a él? (AGN, $S C, R$, doc. 25, f. 612 v.)

Los alcaldes de ambos pueblos comparecieron ante el despacho del protector de naturales en Santafé, quien propuso los términos de un acuerdo que puso fin al litigio. Este acuerdo, aceptado por los indios e impuesto por el virrey en 1758, replicaba la ordenación territorial efectuada por Lesmes de Espinosa. Los cañamomos debían ser reasentados en la Vega de Supía, donde ambas parcialidades compartirían sus resguardos, aunque manteniendo cada una su propio cabildo. También se ordenó establecer una caja de comunidad que asegurara los fondos para el cumplido pago del tributo, y se exoneró a los cańamomos de los que adeudaban hasta esa fecha.

\section{Conclusiones}

En la actualidad, las autoridades de Cañamomo-Lomaprieta sostienen que su resguardo es "uno de los más antiguos del país al haber sido creado mediante Cédula Real expedida por Carlos I de España en Madrid el io de marzo de I540 y siendo redefinidos sus linderos en el año I627" ${ }^{\text {Is }}$. Aunque el examen de los hilos que tejen esta narrativa de origen excede los objetivos de este trabajo, su referencia ilustra las divergencias que persisten en la comprensión del proceso de formación de territorialidades indígenas en la Vega de Supía.

La evidencia muestra que la delimitación de resguardos no se remonta a la temprana fecha mencionada en el relato de los Cañamomo-Lomaprieta. Al igual que otros aspectos de la política indigenista, aquella se efectuó a través de las visitas a la tierra llevadas a cabo por los oidores de la Real Audiencia y otros funcionarios coloniales. Un primer ciclo de visitas (I550-I572) se ocupó principalmente de cuantificar la población tributaria, tasar los tributos y fiscalizar el cumplimiento de reglas relativas al trabajo y tributo indígena. Fue solo en las visitas del segundo ciclo (I593-I670) cuando la conformación de pueblos de indios y la asignación de resguardos ocuparon un lugar central, lo que respondió

I5 Así lo argumentan en la acción de tutela resuelta por la Corte Constitucional en sentencia T-530 del 2016. 
no solo al interés de doctrinar y preservar a la población nativa, sino de liberar tierras para obtener ingresos vía ventas y composiciones.

Las visitas hechas a la región de Anserma evidencian que el cambio de énfasis de cuestiones de trabajo y tributo indígena a cuestiones territoriales no tuvo lugar antes de la década de 1590. En la visita de 1559, el oidor López Medel y el obispo Del Valle se mostraron más interesados en controlar la exacción de tributo y trabajo a los nativos que en delimitar sus tierras, las cuales ni siquiera fueron inspeccionadas directamente por los visitadores. En contraste, la visita de Lesmes de Espinosa Saravia en 1627 marcó un hito en la organización territorial de la región de Anserma. "El señor Don Lesmes" trasladó a los ancestros de los indios de Cañamomo desde el valle de Pirza hacia la Vega de Supía. Al hacerlo, también proporcionó a los cañamomos el fundamento legal para recuperar su resguardo en la Vega más de un siglo después y trazó el marco de referencia que en adelante sería utilizado por todos los actores para argumentar y decidir las disputas de tierras.

Así, en lugar de insistir en el reclamo de sus tierras ancestrales en el valle de Pirza, a mediados de siglo xvin los indios de Cañamomo articularon sus demandas territoriales en los términos definidos por Lesmes de Espinosa Saravia, aun cuando su visita había legalizado el despojo de sus tierras. En cierto modo, los cañamomos habían aprendido que jugar dentro de la legalidad colonial significaba aceptar un orden que establecía posesión por desposesión. Esto implicaba defender sus derechos territoriales en el presente apelando a las mismas decisiones que habían validado el despojo de sus tierras siglos atrás.

Asimismo, la visita de 1627 no solo redefinió territorialidades sino identidades comunales. El reasentamiento de población nativa propició el tránsito de unidades comunales basadas en antiguos cacicazgos redelineados por el reparto de la población en encomiendas (tales eran los "pueblos" enumerados en la visita de 1559), a la emergencia de nuevos partidos — Supía, Cañamomo-Lomaprieta y San Lorenzo - con una composición étnica relativamente heterogénea y cuya identidad comunal se fraguó en torno a la defensa de sus resguardos al amparo de "las ordenanzas del Sr. Don Lesmes". 


\section{$\infty$ \\ B I B L I O G R A F Í́ A}

\section{F U E N T E S P R I M A R I A S}

\section{A. Archivos}

Archivo General de Indias (AGI).

Audiencia de Santafé (AS).

Santa Fe, I7, R. II, n. ${ }^{\circ} 80$, "Relación del Orden que se lleva en la visita general que se va haciendo por el Lic. Miguel de Ibarra, oidor de la Real Audiencia de este

Reyno de los naturales del Distrito de la ciudad de Santa Fe desde el I2 de febrero de $1593^{\prime \prime}$.

Cartas de Audiencia (CA).

"Carta de Lesmes de Espinosa Saravia, oidor de la Audiencia de Santa Fe (I627)".

\section{Archivo General de la Nación, Bogotá, Colombia (AGN).}

Sección Colonia (SC).

Resguardos Antioquia-Cauca-Tolima $(R)$ 53, I

Doc. 25, "Indios de Supía: pleitos por tierras de resguardo, 1757-1759".

Doc. 27. "Indios de Vega de Supía: pleitos por tierras de resguardos, 1706".

Doc. 29. "Anserma: Pleitos por tierras de resguardo, 1594 ".

Doc. 32. "Reintegro de tierras de resguardos, 1750 ".

Visitas del Cauca (VC) 62, I.

Doc. I. "Anserma, Cartago, Arma, Toro: diligencias de visita a minas, 1627”, ff. I-480.

Doc. 2. "Supinga y Tirsa: diligencias de visita, 1627-1628”, ff. 481-702.

Doc. 16. "Sonsón: diligencias de visita, 1627”, ff. 913-942.

\section{Archivo Central del Cauca, Colombia (ACC).}

Sección Colonia $(S C)$.

Col, 3402 (CII-7t), "Numeración de los indios de los pueblos de las jurisdicciones de las ciudades de Anserma, Cartago, Toro y Arma, I728".

\section{Archivo Cabildo Cañamomo-Lomaprieta (ACCL).}

Escritura (E), n. ${ }^{\circ} 263$ de 1903. 


\section{B. Impresos}

Escobar, Fray Jerónimo de. "Relación de Popayán, 1582 ". Cespedesia, n. ${ }^{\circ}$ 45-46, suplemento n. ${ }^{\circ} 4,1983$, pp. $285-307$.

Guillén Chaparro, Francisco. "Memoria de los Pueblos de la Gobernación de Popayán, 1583 ”. Cespedesia, n. ${ }^{\circ} 45-46$, suplemento n. ${ }^{\circ} 4$, 1983, pp. 313-321.

López Medel, Tomás y Berta Ares Queija. Visita de la gobernación de Popayán: libro de tributos, I558-1559. Madrid: Consejo Superior de Investigaciones Científicas, Centro de Estudios Históricos, Departamento de Historia de América, 1989.

Mojica Silva, José. Relación de visitas coloniales. Pueblos, repartimientos y parcialidades indigenas de la provincia de Tunja y de los partidos de La Palma, Muzo, Vélez y Pamplona. Tunja: Imprenta Oficial, 1946.

Montoya, Juan David y José Manuel González, transc. y est. prelim. Visita a la Provincia de Antioquia por Francisco Herrera Campuzano, I6I4-I6I6. Medellín: Universidad Nacional de Colombia, 2010.

Recopilación de las leyes de los Reinos de las Indias. Mandadas imprimir y publicar por la magestad Católica del Rey don Carlos II, nuestro señor. Va dividida en cuatro tomos, con indice general, y alprincipio de cada tomo el especial de titulos que contiene, I681, tomo II, $5 .{ }^{a}$ ed. Madrid: Boix Editor, i84I.

Solano, Francisco de. Cedulario de Tierras. Compilación de Legislación Agraria Colonial,

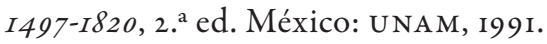

\section{FUENTESSECUNDARIAS}

Ares Queija, Berta. "Estudio preliminar: El oidor Tomás López Medel, visitador de Popayán”. Visita de la gobernación de Popayán: libro de tributos, I558-I559. Madrid: Consejo Superior de Investigaciones Científicas, Centro de Estudios Históricos, Departamento de Historia de América, 1989, pp. XV-LV.

Bonnett Vélez, Diana. Tierra y comunidad. Un problema irresuelto. El caso del altiplano cundiboyacense (Virreinato de la Nueva Granada) I750-I800. Bogotá: Instituto Colombiano de Antropología e Historia; Universidad de Los Andes, 2002.

Caicedo, Luis Javier. Cinco siglos de historia de Riosucio (Caldas). Con énfasis en la conformación del territorio. Pereira: UTP - Municipio de Riosucio, 2018.

---. “Transcripción de documentos históricos sobre Riosucio, Caldas”. Ciencia Nueva. Revista de Historia y Politica, vol. 2, n. ${ }^{\circ}$ I, 2018, pp. 200-213. DoI: https://doi. org/10.22517/25392662.1827I. 
Céspedes, Guillermo. "La Visita como institución indiana”. Anuario de Estudios Americanos, vol. III, I946, pp. 984-1025.

Colmenares, Germán. Historia económica y social de Colombia I, I537-I7Ig. Bogotá: Tercer Mundo, 1997.

Cuesta, Rómulo. Tomás. Riosucio: Álvaro Gärtner y Grupo de Apoyo a las Danzas del Ingrumá, 2000.

Escobar, María Elvira. "Sírvase reconocer todos los indios que estamos en el partido de Lomaprieta”. Virajes. Revista de Antropología y Sociología, vol. I, I999, pp. 6-17.

Eugenio Martínez, María Ángeles. Tributo y trabajo del indio en Nueva Granada (De Jiménez de Quesada a Sande). Sevilla: Escuela de Estudios Hispano-Americanos, 1977.

Fals-Borda, Orlando. "Indian Congregations in the New Kingdom of Granada: Land Tenure Aspects, I595-1850". The Americas, vol. I3, n. ${ }^{\circ}$, 1957, pp. 331-351. JSTOR, www. jstor.org/stable/979439. DOI: https://doi.org/ı0.2307/979439

Friede, Juan. Vida y luchas de don Juan del Valle, primer obispo de Popayán y protector de indios. Estudio documental basado en investigaciones realizadas en los archivos de Colombia, España y el Vaticano. Popayán: Arzobispado de Popayán, I96I.

---. Los Quimbaya bajo la dominación española. Estudio documental, I539-1810. Bogotá: Banco de la República, 1963.

---. "De la encomienda a la propiedad territorial y su influencia sobre el mestizaje”. Anuario Colombiano de Historia Social y de la Cultura, n. ${ }^{4}$, 1969, pp. 35-61. DoI: 10.15446/achsc.

Gärtner, Álvaro. Los misteres de las minas. Crónica de la colonia europea más grande de Colombia en el siglo XIX, surgida alrededor de las minas de Marmato, Supia y Riosucio. Manizales: Universidad de Caldas, 2005.

González, Margarita. El Resguardo en el Nuevo Reino de Granada, 2. ed. Bogotá: Inéditos, 1979 .

Graubart, Karen B. "Shifting Landscapes. Heterogeneous Conceptions of Land Use and Tenure in the Lima Valley". Colonial Latin American Review, vol. 26, n. ${ }^{\circ}$ I, 2017 , pp. 62-84. DOI: 10.1080/10609164.2017.1287328.

Herrera Ángel, Martha. “Ordenamiento espacial de los pueblos de indios: dominación y resistencia en la sociedad colonial”. Fronteras de la Historia, vol. 2, n. ${ }^{\circ}$ 2, 1998, pp. 93-128. DOI: https://doi.org/I0.22380/20274688.757.

---. Ordenarpara controlar. Ordenamiento espacial y control politico en las llanuras del Caribe y en los Andes centrales neogranadinos. Siglo XVIII. Bogotá: La Carreta, 200I.

---. Popayán: La unidad de lo diverso. Territorio, población y poblamiento en la provincia de Popayán, siglo XVIII. Bogotá: Universidad de los Andes, 2009. 
Herzog, Tamar. "Colonial Law and 'Native Customs': Indigenous Land Rights in Colonial Spanish America”. The Americas, vol. 63, n. ${ }^{3}$, 2013, pp. 303-321. DoI: https://doi. org/10.1353/tam.2013.0016.

Jaramillo Uribe, Jaime. "La población indígena de Colombia en el momento de la conquista y sus transformaciones posteriores. Primera parte”. Anuario Colombiano de Historia Social y de la Cultura, n. ${ }^{\circ}$ 2, 1964, pp. 239-293.

---. "La Administración colonial”. Nueva Historia de Colombia. I. Colombia Indígena, Conquista y Colonia, editado por Jaime Jaramillo Uribe. Bogotá: Planeta, 1989, pp. 175-192.

Luna, Lola. Resguardos coloniales de Santa Marta y Cartagena y resistencia indigena. Bogotá: Fondo de Promoción de la Cultura del Banco Popular, I993.

Mörner, Magnus. La corona española y los foráneos en los pueblos de indios de América. Estocolmo: Almqvist \& Wiksell, 1970.

Owensby, Brian P. Empire of Law and Indian Justice in Colonial Mexico. Stanford: Stanford University Press, 2008.

Quiroga Zuluaga, Marcela. "El proceso de reducciones entre los pueblos muiscas de Santafé durante los siglos XVI y XVII”. Historia Crítica, n. 52, 201 4, pp. 179-203. DoI: https:// doi.org/10.7440/histcrit52.2014.08.

Reina Mendoza, Sandra. Traza urbana y arquitectura en los pueblos de indios del altiplano cundiboyacense. Siglo XVI a XVIII: el caso de Bojacá, Sutatausa, Tausa y Cucaita. Bogotá: Universidad Nacional de Colombia, 2008.

Romero Sánchez, Guadalupe. Los pueblos de indios en Nueva Granada. Granada: Editorial Atrio, 2010.

Ruiz Rivera, Julian. "Las visitas a la tierra en el siglo XVII como fuente de historia social". Estudios sobre Politica Indigenista Española en América, vol. I. Valladolid: Universidad de Valladolid, 1975, pp. 197-214.

Salcedo Salcedo, Jaime. "Los pueblos de indios en el Nuevo Reino de Granada y Popayán”. Pueblos de indios. Otro urbanismo en la región andina, coordinado por Ramón Gutiérrez. Quito: Ediciones Abya-Yala, 1993, pp. 179-203.

Sánchez Bella, Ismael. Derecho indiano: Estudios I. Las visitas generales en la América Española. Siglos XVI-XVII. Pamplona: Eunsa, I99I.

Sentencia T-530 de 2016. Corte Constitucional, Colombia. https://www.corteconstitucional. gov.co/relatoria/2016/t-530-16.htm

Solano, Francisco de. Ciudades hispanoamericanas y pueblos de indios. Madrid: Consejo Superior de Investigaciones Científicas, 1990. 
Tapasco, José Silvio. Reseña histórica de mi pueblo. Resguardo indígena de San Lorenzo. Riosucio: s. e., 2010.

Zuluaga Gómez, Víctor. Una historia pendiente. Indigenas desplazados en el Antiguo Caldas. Pereira: Gráficas Buda, 2006. 